\title{
O DIREITO SISTÊMICO E AS REDES DE APOIO: INTERSEÇÕES COMPLEMENTARES COMO FORMA DE ACESSO À JUSTIÇA
}

\author{
Janaina Paiva Sales ${ }^{1}$ \\ Maísa de Souza Lopes ${ }^{2}$
}

\section{Resumo:}

O presente artigo tem por escopo analisar de que forma as redes de apoio influenciam na aplicação do Direito Sistêmico. Analisaremos o Direito Sistêmico em sua conceituação, fundamentação jurídica que lhe concede bases legais, bem como sua aplicabilidade diante deste cenário. Após, verificar-se-á as interseções existentes entre as redes de apoio e o Direito Sistêmico como forma de acesso à Justiça na perspectiva da autocomposição. A metodologia utilizada será a bibliográfica e documental.

Palavras-chave: Direito sistêmico; Redes de apoio; Interseções; Acesso à Justiça; Constelação Familiar

\section{SYSTEMIC LAW AND SUPPORT NETWORKS: COMPLEMENTARY INTERSECTIONS AS A FORM OF ACCESS TO JUSTICE}

\begin{abstract}
:
The purpose of this article is to analyze how support networks influence the application of Systemic Law. We will analyze Systemic Law in its conceptualization, a legal foundation that grants it legal bases, as well as its applicability in this scenario. Afterwards, the intersections between support networks and Systemic Law will be verified as a way of accessing Justice from the perspective of self-composition. The methodology used will be bibliographic and documentary.
\end{abstract}

Keywords: Systemic Law; Networks of Support; Intersections; Access to justice; Family Constellation

\section{INTRODUÇÃO}

O artigo propõe o estudo das redes de apoio ressaltando sua importância para a construção do indivíduo fornecendo solidez para o seu desenvolvimento social. Analisaremos

\footnotetext{
${ }^{1}$ Advogada em Salvador/BA. Mestre em Direito pela Faculdade Autônoma de São Paulo/SP - FADISP. Doutoranda do Programa de Pós Graduação em Família na Sociedade Contemporânea da Universidade Católica do Salvador - UCSAL. Professora de Direito. janapaivas@yahoo.com.br. Endereço postal: Rua Jeribá, n. 325, sl. 32, Campo Grande/MS

${ }^{2}$ Doutora em Direito pela Faculdade Autônoma de São Paulo/SP - FADISP. Advogada e professora especialista em Direito Civil. maisalopes@ outlook.com. Endereço postal: Rua Jeribá, n. 325, sl. 32, Campo Grande/MS
} 
o Direito Sistêmico em sua conceituação, fundamentação jurídica que lhe concede bases legais, bem como sua aplicabilidade diante deste cenário.

A fim de cumprir esse mister, verificaremos as interseções entre os institutos, ressaltando os pontos mais relevantes, sem, contudo, a intenção de esgotar o tema. Feita essa análise, comentaremos os pontos de contato como forma de acesso à Justiça na perspectiva da autocomposição e apresentaremos as conclusões finais.

É notório o avultamento das demandas dirigidas ao Poder Judiciário, o que acarreta um açodamento de trabalho aos Servidores, Auxiliares da Justiça, Magistrados, Advogados, Operadores do direito em geral com uma carga laboral excessiva, vez que a atividade jurisdicional não passa pela mera produção de decisões em massa. Devem ser observadas as especificidades de cada situação concreta para que o ideal da justiça justa seja atingido da forma mais próxima do possível.

No entanto, essa não é a realidade experimentada por grande parte dos Operadores do Direito e Tribunais do país. É cada vez mais comuns decisões judiciais que não refletem a realidade das partes, gerando a quase obrigatoriedade da interposição recursal para ver reformados tais julgamentos, o que torna o procedimento mais moroso, dispendioso, cansativo e, principalmente, desacreditado.

O conteúdo relacional do conflito constitui-se, por vezes, um entrave às discussões. A ausência do diálogo pode levar ao prematuro ajuizamento de demandas que nascem, por isso mesmo, indefinidas em seus contornos, "confusas", porque frutos de emoções incompreendidas, ou mal digeridas.

Aqui não existe propriamente lesão, ou ameaça de lesão a direito, mas pessoas que, inundadas em emoções, não se permitem refletir sobre interesses em aparente antagonismo. Vale ressaltar que todos têm assegurado pelo texto constitucional vigente - art., $5^{\circ}, \mathrm{XXXV}^{3}$,

\footnotetext{
${ }^{3}$ Art. $5^{\circ}$ Todos são iguais perante a lei, sem distinção de qualquer natureza, garantindo-se aos brasileiros e aos estrangeiros residentes no País a inviolabilidade do direito à vida, à liberdade, à igualdade, à segurança e à propriedade, nos termos seguintes: (...) XXXV - a lei não excluirá da apreciação do Poder Judiciário lesão ou ameaça a direito;
} 
o direito de ver o Estado Juiz decidir sobre o seu caso, mas é, também, dever de todos a construção de uma sociedade justa e pacífica ${ }^{4}$.

O tema abordado requer uma análise transversal dos conteúdos interdisciplinares (jurídicos, psicológicos, sociais etc) na busca do acesso a uma justiça justa, o que revela a importância do tema e sua atualidade.

A metodologia que será usada na pesquisa é a hipotético-dedutiva, pois planeja-se a partir do estudo do Direito Sistêmico no ordenamento jurídico pátrio, compreender em que medida se pode aplicá-lo na realidade social. Ainda, a pesquisa será essencialmente bibliográfica e documental.

\section{REDES DE APOIO}

O ser humano, objeto central das relações humanas, é um ser múltiplo. Diferente não poderia ser a abordagem que busca, de forma equilibrada e leal, compreender, ainda que parcialmente, sua natureza.

Uma das mais importantes dimensões do desenvolvimento humano e o bemestar do indivíduo na literatura psicológica, é o apoio social e afetivo. Sua importância para a Psicologia reside no fato de ser uma interface entre a pessoa e o ambiente social do qual ela faz parte, tendo influência direta no seu desenvolvimento 5 .

Dessa forma, entendemos que a rede de relacionamentos que acompanham o indivíduo é fundamental para a solução de suas questões e de seu posicionamento diante da vida $^{6}$.

\footnotetext{
${ }^{4}$ Art. $3^{\circ}$ Constituem objetivos fundamentais da República Federativa do Brasil: I - construir uma sociedade livre, justa e solidária;

${ }^{5}$ BRITO, R.C.; KOLLER, S.H. Desenvolvimento humano e redes de apoio social e afetivo. In: CARVALHO, A. M. (Org.) O mundo social da criança: natureza e cultura em ação. São Paulo: Casa do Psicólogo, 1999. Cap. 7, p. 115).

${ }^{6} \mathrm{O}$ apoio social e afetivo está relacionamento com a percepção que a pessoa tem de seu mundo social, como se orienta nele, suas estratégias e competências para estabelecer vínculos, e com os recursos que esse lhe oferece como proteção e força, frente a situações de risco que se apresentam. (Pierce, Sarason, Sarason, Joseph \& Henderson, 1996 apud BRITO, R.C.; KOLLER, S.H. (1999, p. 115).
} 
O conceito de rede de apoio possui diversos aspectos. Para este trabalho, será utilizada a seguinte definição, de Brito, R.C.; Koller, S.H. (1999): “Ao conjunto de sistemas e de pessoas significativas que compõem os elos de relacionamentos recebidos e percebidos do indivíduo denomina-se rede de apoio social"”.

Brito, R.C.; Koller, S.H. (1999) tratam de como a ausência ou presença de vínculos e relações interfere nos relacionamentos de maneira preponderante, influenciando-os social e emocionalmente.

A existência, ou não, de rede de apoio efetiva motiva no desenvolvimento de estratégias para lidar com situações de conflito e de stress. De acordo com o modelo denominado de Escolta de apoio social e afetivo trazido por Antonucci e Jackson (1987):

(...) é composto pelas interações sociais experimentadas ao longo do desenvolvimento do indivíduo: a primeira relação de apego, os papéis desempenhados e o apoio social recebido e percebido, entre outras. O termo escolta foi tomado emprestado da Antropologia, para evocar uma imagem composta de camadas protetivas, ou seja, a pessoa é envolvida por sua família, amigos, parceiros comunitários, que a circundam e a ajudam a enfrentar os desafios da vida e compartilhar suas experiências.

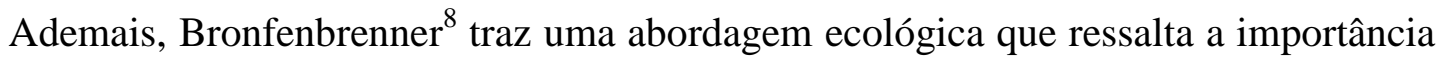
das redes de apoio como uma série de estruturas encaixadas - umas dentro das outras. Internamente nas relações mais próximas tem-se um microssistema. Do conjunto deste surge o mesossistema. "Aqueles ambientes nos quais a pessoas não participa diretamente, mas dos quais recebe influência indireta, estão em seu exossistema." " Já o macrossistema, que é o mais amplo, manifesta-se no estilo de vida, valores, organização das instituições sociais comuns a uma determinada cultura.

Para o autor supracitado tal abordagem traz em si uma concepção evolutiva do indivíduo em seu ambiente e sua capacidade de interagir, descobrir, criar, alterar o que está a sua volta. "Nessa perspectiva, pessoas que têm fortes redes de apoio social e afetivo são

\footnotetext{
${ }^{7}$ BRITO, R.C.; KOLLER, S.H. (1999)

${ }^{8}$ Ibidem, p. 117.

${ }^{9}$ Ibidem, loc. cit.
} 
maiscompetentes para oferecer apoio, e para estabelecer relações próximas e significativas, fazendo parte da rede de outras pessoas."

Tal percepção repercute de maneira a fortalecer elos sociais e afetivos, bem como sugere um maior equilíbrio frente às situações adversas, funcionando como verdadeiras escoltas em torno dos membros da rede, que se fortalecem mutuamente. É nessa perspectiva que o Direito Sistêmico se vale das redes de apoio para o enfrentamento dos conflitos e que foram (ou podem ser) levadas à apreciação do Poder Judiciário.

A ajuda para o momento de fragilidade exposta, ainda quando da decisão voluntária de submeter sua questão ao olhar do Direito Sistêmico, é de importante valia no âmbito psicológico e social do indivíduo. Embora praticado com a concordância das partes e supervisão de Magistrados, Auxiliares da Justiça e Operadores do Direito, há ainda uma certa insegurança quanto à exposição de sua questão, de sua vulnerabilidade. No entanto, os resultados demonstram que não há motivos para tal sentimento e os ganhos com a adoção, sempre voluntária por parte dos envolvidos, são reais e expressivos.

O indivíduo devidamente amparado pelas redes de apoio é mais saudável e capaz de solucionar, por ele mesmo, suas questões. A contrario sensu aquele que se insere de maneira desamparada - em relação à suas redes - no contexto social tende a concentrar relações conflituosas, que se mal resolvidas podem evoluir para as questões que batem à porta do Poder Judiciário requerendo a sua chancela para a solução.

O Direito por sua vez é a ciência que cuida da solução dos conflitos levando como ultima ratio à chancela do Estado para resolvê-los mediante a imposição de uma solução legal. Aqui se apresenta a primeira interseção.

\section{DIREITO SISTÊMICO}

A expressão Direito Sistêmico foi cunhada pelo Magistrado do Tribunal de Justiça da Bahia Sami Storch ${ }^{11}$, que já aplica o método desde 2012. Ele tomou conhecimento da técnica

\footnotetext{
${ }^{10}$ Ibidem, loc. cit.
} 
em uma terapia pessoal, antes de ingressar na magistratura e, ao aplicá-la às disputas judiciais, surpreendeu-se com os bons resultados.

Amilton Plácido da Rosa ${ }^{12}$ conceitua Direito Sistêmico como:

O Direito Sistêmico é, antes de tudo, uma postura. É uma nova forma de viver e de se fazer justiça, buscando o equilíbrio entre o dar e o receber, de modo a trazer paz para os envolvidos em um conflito.

O Direito Sistêmico, em termos técnico-científico, é um método sistêmicofenomenológico de solução de conflitos, com viés terapêutico, que tem por escopo conciliar, profunda e definitivamente, as partes, em nível anímico, mediante o conhecimento e a compreensão das causas ocultas geradoras das desavenças, resultando daí paz e equilíbrio para os sistemas envolvidos. (grifo nosso).

Assim sendo, o Direito Sistêmico, como o próprio nome já nos sugere, tem por base a aplicação dos princípios da Constelação Sistêmica em conformidade com os ensinamentos do alemão Bert Hellinger.

\section{FUNDAMENTAÇÃO JURÍDICA DO DIREITO SISTÊMICO}

A sustentação jurídica do Direito Sistêmico encontra bases no próprio ordenamento legal brasileiro, conforme passaremos a expor.

Prescreve o Preâmbulo da Constituição Federal de 1988 que o Brasil adota o Estado Democrático $^{13}$. Tal afirmação reverbera de maneira forte em todo o sistema jurídico-social e institucional do país. E assim o é em razão da escolha pela democracia ${ }^{14}$.

11 A expressão "Direito sistêmico", termo cunhado por mim quando lancei o blog Direito Sistêmico (direitosistemico.wordpress.com), surgiu da análise do Direito sob uma ótica baseada nas ordens superiores que regem as relações humanas, conforme demonstram as constelações familiares desenvolvida por Hellinger. Disponível em: https://direitosistemico.wordpress.com/ . Acesso em 22/04/2019

12 ROSA, Amilton Plácido. Direito Sistêmico e Constelação Familiar. Disponível em: http://www.cartaforense.com.br/conteudo/entrevistas/direito-sistemico-e-constelacao-familiar/16914. Acesso em: 22/04/2019.

${ }^{13}$ Nós, representantes do povo brasileiro, reunidos em Assembleia Nacional Constituinte para instituir um Estado Democrático, destinado a assegurar o exercício dos direitos sociais e individuais, a liberdade, a segurança, o bem-estar, o desenvolvimento, a igualdade e a justiça como valores supremos de uma sociedade fraterna, pluralista e sem preconceitos, fundada na harmonia social e comprometida, na ordem interna e internacional, com a solução pacífica das controvérsias, promulgamos, sob a proteção de Deus, a seguinte 
Além da escolha pela democracia como opção do poder constituinte originário, constitui-se um verdadeiro balizador do texto constitucional a solução pacífica das controvérsias (vide Preâmbulo da Carta Constitucional de 1988). Ademais, coaduna com os objetivos fundamentais elencados no texto da Lei Maior de 1988 que rege nosso ordenamento, qual seja, o de construir uma sociedade livre, justa e solidária.

O Direito deve respeito a esse mandamento constitucional, além de promover e estimular sua observância. Ao promover a Justiça, enquanto um valor do Estado, este deve fomentar meios alternativos à imposição estatal para solução de conflitos, como forma de efetivo acesso à Justiça.

Tal diretriz está claramente mencionada na parte inicial da Resolução no 125, de 29 de novembro de 2010, do Conselho Nacional de Justiça $-\mathrm{CNJ}^{15}$. Vejamos:

$$
\text { (...) }
$$

CONSIDERANDO que a eficiência operacional, o acesso ao sistema de Justiça e a responsabilidade social são objetivos estratégicos do Poder Judiciário, nos termos da Resolução/CNJ nº 70, de 18 de março de 2009;

CONSIDERANDO que o direito de acesso à Justiça, previsto no art. $5^{\circ}$, XXXV, da Constituição Federal além da vertente formal perante os órgãos judiciários, implica acesso à ordem jurídica justa e a soluções efetivas;

CONSTITUIÇÃO DA REPÚBLICA FEDERATIVA DO BRASIL. (Preâmbulo da Constituição da República Federativa do Brasil de 1988) (grifo nosso).

${ }^{14}$ (...) Preâmbulo da Constituição, no qual se contém a explicitação dos valores que dominam a obra constitucional de 1988 (...). Não apenas o Estado haverá de ser convocado para formular as políticas públicas que podem conduzir ao bem-estar, à igualdade e à justiça, mas a sociedade haverá de se organizar segundo aqueles valores, a fim de que se firme como uma comunidade fraterna, pluralista e sem preconceitos (...). E, referindo-se, expressamente, ao Preâmbulo da Constituição brasileira de 1988, escolia José Afonso da Silva que "O Estado Democrático de Direito destina-se a assegurar o exercício de determinados valores supremos. 'Assegurar', tem, no contexto, função de garantia dogmático-constitucional; não, porém, de garantia dos valores abstratamente considerados, mas do seu 'exercício'. Este signo desempenha, aí, função pragmática, porque, com o objetivo de 'assegurar', tem o efeito imediato de prescrever ao Estado uma ação em favor da efetiva realização dos ditos valores em direção (função diretiva) de destinatários das normas constitucionais que dão a esses valores conteúdo específico" (...). Na esteira destes valores supremos explicitados no Preâmbulo da Constituição brasileira de 1988 é que se afirma, nas normas constitucionais vigentes, o princípio jurídico da solidariedade. [ADI 2.649, voto da rel. min. Cármen Lúcia, j. 8-5-2008, P, DJE de 17-10-2008. Disponível em: http://www.stf.jus.br/portal/constituicao/artigoBd.asp?item=2. Acesso em 28/04/2019. (grifo nosso).

${ }^{15}$ CONSELHO NACIONAL DE JUSTIÇA. Resolução n. 125, 2010. Disponível em: https://atos.cnj.jus.br/atos/detalhar/atos-normativos?documento=156. Acesso em 22/08/2019. 
CONSIDERANDO a necessidade de se consolidar uma política pública permanente de incentivo e aperfeiçoamento dos mecanismos consensuais de solução de litígios;

$(\ldots)$

CONSIDERANDO a relevância e a necessidade de organizar e uniformizar os serviços de conciliação, mediação e outros métodos consensuais de solução de conflitos, para lhes evitar disparidades de orientação e práticas, bem como para assegurar a boa execução da política pública, respeitadas as especificidades de cada segmento da Justiça;

CONSIDERANDO que, por isso, cabe ao Judiciário estabelecer política pública de tratamento adequado dos problemas jurídicos e dos conflitos de interesses, que ocorrem em larga e crescente escala na sociedade, de forma a organizar, em âmbito nacional, não somente os serviços prestados nos processos judiciais, como também os que possam sê-lo mediante outros mecanismos de solução de conflitos, em especial dos consensuais, como a mediação e a conciliação; (grifos no original).

O objeto aqui analisado está claramente alinhado com a Resolução no 125 do Conselho Nacional de Justiça $-\mathrm{CNJ}^{16}$, que dispõe sobre a Política Judiciária Nacional de tratamento adequado dos conflitos de interesses no âmbito do Poder Judiciário, assim como encontra esteio na lei $n^{\circ}$ 13. 105, de 16 de março de 2015 - Código de Processo Civil ${ }^{17}$ - como uma das formas de solução consensual de conflito $^{18}$ como descrito na própria lei como “outros métodos de solução consensual de conflito."

Na Resolução supracitada há a expressa disposição do incentivo e prática de ações que estimulem a prática da autocomposição ${ }^{19}$, assim como a criação de Centros Judiciários de

\footnotetext{
${ }^{16}$ Ibidem

${ }^{17}$ Art. $3^{\text {o }}$ Não se excluirá da apreciação jurisdicional ameaça ou lesão a direito. Note-se que há a repetição do contido no art. $5^{\circ}$, inciso XXXV da Constituição Federal de 1988.
}

$\S 3^{\circ}$ A conciliação, a mediação e outros métodos de solução consensual de conflitos deverão ser estimulados por juízes, advogados, defensores públicos e membros do Ministério Público, inclusive no curso do processo judicial. (grifo nosso)

18 O Professor Fredie Didier Jr lembrando os ensinamentos de Diogo Assumpção Rezende Almeida (" $O$ princípio da adequação e os meios de solução de conflitos”. Revista de Processo. São Paulo:RT, 2011v. 195, p. 185 e segs) ressalta a importância de se falar em "meios adequados de solução de conflitos" designação que engloba todos os meios, jurisdicionais ou não, estatais ou não, e não mais "meios alternativos de solução de conflitos".(grifo nosso) (DIDIER JR, Fredie. Curso de direito processual civil: introdução ao direito processual civil, parte geral e processo de conhecimento - 20ed. Salvador: Ed. Jus Podivm, 2018, p. 199).

${ }^{19}$ Art. $4^{\text {o }}$ Compete ao Conselho Nacional de Justiça organizar programa com o objetivo de promover ações de incentivo à autocomposição de litígios e à pacificação social por meio da conciliação e da mediação. Resolução $n^{\circ} 125$ do Conselho Nacional de Justiça - CNJ 
Solução de Conflitos e Cidadania (art. $7^{\circ}$ ) com a determinação de que tais procedimentos deverão ser pré-processuais (art. $8^{\circ}, \S 1^{\circ}$ ), numa clara observância à Constituição Federal de 1988 que elevou ao patamar de direito e garantia fundamental a celeridade e a duração razoável dos processos ${ }^{20}$. O que sem dúvidas é uma extensão do Princípio da Dignidade da Pessoa Humana $^{21}$, fundamento da República Federativa do Brasil, no que tange às relações processuais.

Há, no entanto, a necessidade de se fazer uma sucinta e breve diferenciação sobre os meios de solução consensual de conflitos. ${ }^{22}$

Para FREDDIE JR (2018, p. 199), a autotutela é "uma solução de conflito de interesses que se dá pela imposição da vontade de um deles, com o sacrifício do interesse do outro. Solução egoísta e parcial do litígio."23 É solução proibida pela nossa legislação, cabendo como exceção de autotutela permitida, p. ex., o direito de greve, a legítima defesa dentre outros.

A autocomposição é "forma de solução do conflito pelo consentimento espontâneo de um dos contendores em sacrificar o interesse próprio, no todo ou em parte, em favor do interesse alheio. É a solução altruísta do litígio (...) (art. $\left.3^{\circ}, \S 2^{\circ}, \mathrm{CPC}\right) .{ }^{24}$

Já a heterocomposição consiste em técnica de solução de conflito onde "um terceiro substitui a vontade das partes e determina a solução do problema apresentado. (...)"25 Importante salientar que esse terceiro deve ser imparcial e desinteressado na solução do

\footnotetext{
${ }^{20}$ Art. $5^{\circ}$ inciso LXXVIII - a todos, no âmbito judicial e administrativo, são assegurados a razoável duração do processo e os meios que garantam a celeridade de sua tramitação.

${ }^{21}$ Art. $1^{\circ}$ A República Federativa do Brasil, formada pela união indissolúvel dos Estados e Municípios e do Distrito Federal, constitui-se em Estado Democrático de Direito e tem como fundamentos: III - a dignidade da pessoa humana;

${ }^{22}$ Analisaremos autotela, autocomposição e heterocomposição em seus conceitos básicos tomando como referencial o Professor Fredie Didier Jr. Tal análise se dará apenas como orientação do tema abordado no presente Artigo sem a pretensão de esgotar suas nuances.

${ }^{23}$ Ibidem, p. 200.

${ }^{24}$ Ibidem, p. 201.

${ }^{25}$ Ibidem, p. 188.
} 
conflito. O exemplo clássico dessa vertente é o Estado-Juiz representado pela figura do Magistrado.

Como se percebe o Direito Sistêmico se enquadra como autocomposição, pois há a necessidade de voluntariedade na aceitação da prática sistêmica como meio adequado para solução do conflito apresentado perante o Poder Judiciário.

Tem sido nessa esteira o entendimento dos Tribunais sobre a aplicação do Direito Sistêmico. Vejamos:

(...) Um dos objetivos do Processo Civil atual é criar condições para que o juiz possa proferir decisão de forma mais rente à realidade fática subjacente à causa e, desse modo, proporcionar às partes a obtenção de solução de mérito justa, efetiva e em prazo razoável (artigo $4^{\circ}$ e $6^{\circ}$ do CPC). É justamente no âmbito desse novo paradigma e bases de princípios do Processo Civil atual, que pela via CONCILIATÓRIA, situa-se a dinâmica sistêmica das Constelações ... Familiares e o Direito Sistêmico. (...) (Ap. Civel no 70076720119, $8^{\text {a }}$ Câmara Cível, Tribunal de Justiça do Rio Grande do Sul. Rel. Rui Portanova, julgado em 30/02/2018. Data da publicação: Diário da Justiça: 11/09/2018). (grifo nosso).

Importante é o reconhecimento, pelo Poder Judiciário, da aplicação das técnicas advindas do Direito Sistêmico, não raras vezes os Magistrados suspendem o processo a fim de que se tente, pela via da autocomposição, a solução da questão.

Feitas essas considerações, diante da manifesta intenção de solucionar o conflite pela via da autocomposição, converto o julgamento em diligência e determino a remessa dos autos ao Núcleo Permanente de Métodos Consensuais de Solução de Conflitos e Cidadania (Nupemec), a fim de que a equipe de trabalho viabilize a realização de oficina de Direito Sistêmico, no prazo de 40 (quarenta) dias. (...) (Ap. 27326/2018, Desa. Clarice Claudino da Silva, $2^{\mathrm{a}}$ Câmara de Direito Privado, julgado em 01/10/2018, publicado no DJE 08/10/2018.) (grifos nosso).

Não é demais (re) lembrar que, devido a imperativo constitucional ${ }^{26}$, a qualquer momento qualquer das partes pode desistir do procedimento pré-processual e continuar com a heterocomposição como caminho para a solução de sua querela.

\section{O DIREITO SISTÊMICO NA PRÁTICA}

\footnotetext{
${ }^{26}$ Vide art. $5^{\circ}$ inciso XXXV da Constituição Federal de 1988.
} 
A prática consiste na participação voluntária dos interessados, de forma a reproduzir a situação de conflito. Através dessa representação, o facilitador do trabalho conduz a vivência de maneira a identificar a posição dos familiares envolvidos demonstrando suas conexões com a contenda.

Diante da consciência trazida pela representação das queixas é possível que se identifique as prováveis soluções para o caso concreto. São as partes que, por meio do reconhecimento de dada situação específica e da assimilação do que tal questão representa para o seu sistema, estão aptas a propor e aceitar a solução para seu próprio problema. É a expressão da autocomposição como meio adequado de solução de conflito em sua mais pura essência.

Vejamos a representação abaixo ${ }^{27}$ :

\section{Constelação Familiar}

A Constelação Familiar

investiga as relações interpessoais de

determinado sistema familiar, mostrando

as conexões entre as gerações

Pessoas que representam familiares

assumem sua posição dentro da

constelação, descrevem o que sentem

e reproduzem a dinâmica

psicológica da familia
Temas mais comuns:

- Dificuldades de relacionamento

- Mortes na familia

- Separações

- Tragédias

- Doenças

- Problemas financeiros

- Heranças

- Traumas

- Vícios

Figura 1

O caso que será analisado é o seguinte ${ }^{28}$ : Aos 35 anos de idade, a filha era viciada em crack e desenvolveu transtornos mentais. Vinha ameaçando e agredindo pessoas na rua com uma faca e quebrava as coisas dentro de casa. Além disso, não aceitava qualquer ajuda ou tratamento médico e se recusava a tomar os remédios receitados, motivo que levou a

${ }^{27}$ Disponível em: http://www.cnj.jus.br/noticias/cnj/86434-constelacao-familiar-no-firmamento-da-justica-em16-estados-e-no-df . Acesso em 22/04/2019.

${ }^{28}$ Ibidem 
mãe entrar na Justiça para obrigar a filha a se internar. A liminar foi concedida pelo juiz e a filha foi internada.

Segue abaixo trechos de uma matéria sobre a aplicação do Direito Sistêmico pelo Magistrado Sami Storch $^{29}$ no caso acima exposto:

(...) as partes dos processos são convidadas a participar de Constelações Familiares de forma voluntária. A eventual negativa do convite não interfere no andamento ou no resultado processual.

"Mas, se vierem, têm muito a ganhar", diz o juiz Sami Storch, que costuma organizar as constelações pelos temas dos processos - por exemplo, partes de processos de divórcio ou disputa de guarda de filhos. Na Constelação Familiar de que a senhora - que aqui chamaremos de Laura - participou, estavam presentes as partes envolvidas nas ações, profissionais do direito, estudantes e outros convidados.

$(\ldots)$

A Constelação foi iniciada com pessoas representando a filha viciada, o pai de Laura, o avô da garota e o próprio crack. O personagem que fazia o papel da droga se colocou entre mãe e filha, impedindo que se comunicassem. Durante a experiência, algumas histórias vieram à tona: Laura, a mãe, havia sido forçada pelo pai a se casar, motivo pelo qual cortara o contato com ele, o que a fizera sofrer muito. E a exclusão do avô gerava grande mágoa também na neta.

Segundo Bert Hellinger, o inventor da Constelação Familiar, a droga representa para o viciado alguém da família que foi excluído - geralmente o pai. Depois de muita resistência, Laura conseguiu encarar a pessoa que representava o seu pai e o abraçou. Neste momento, o juiz interrompeu a sessão de Constelação.

Os resultados geralmente tem grande expressão fora do âmbito judicial. Vejamos:

Dias depois, a assistente social comunicou ao juiz que Laura estava bem mais tranquila e havia retomado contato com sua filha, em um diálogo inicialmente travado por telefone. A instituição de tratamento informou, também, que houve melhora sensível no quadro psicológico da filha. Resultados como esse são comuns após a Constelação Familiar - mães reestabelecem o contato com filhos, adolescentes que cumprem medida socioeducativa deixam a violência de lado, pessoas que disputam a guarda de crianças entram em acordo ${ }^{30}$.

\footnotetext{
${ }^{29}$ Ibidem

${ }^{30}$ Ibidem.
} 
Observa-se da análise desse caso prático a eficiência da aplicação do Direito Sistêmico. Conseguinte, acrescentaremos a intersecções entre as redes de apoio e o Direito Sistêmico como forma de acesso a justiça.

\section{INTERSEÇÕES ENTRE AS REDES DE APOIO E O DIREITO SISTÊMCO COMO FORMA DE ACESSO À JUSTIÇA}

Como podemos notar o Direito Sistêmico possui um forte e significativo viés interdisciplinar.

Diante dos conceitos tratados até aqui, percebe-se claramente que a influência do ambiente ao nosso redor para a solução de conflitos, influenciando fortemente na autocomposição. Afinal existe a inter-relação e interação dos indivíduos com o ambiente em que vivem através de suas reações. Essas podem ser de aproximação no caso de afetos ou de repulsão para o caso de não-afetos.

Através do arcabouço psicológico-afetivo-social gerado e transmitido via "elos dessa corrente" tais reconhecimentos e pertencimentos podem ser mais fáceis de serem aceitos ou não.

As questões familiares permeiam os conflitos apresentados ao Direito Sistêmico (vide o exemplo da figura 1 neste estudo): seja de forma direta como dificuldades de relacionamento, separações ou de indiretamente como vícios, doenças, etc.

A reflexão a ser feita é no sentido de conjugar a importância das redes de apoio social e afetivamente fortes o bastante para oferecer ao indivíduo - elo desse encadeamento sustentação para que, ao se deparar com conflitos, exista abertura e inclinação para a composição destes. Assim, as redes de apoio se revelam alicerce de uma sociedade saudável.

O Poder Judiciário, por sua vez, por meio do Direito Sistêmico, devolve aos litigantes, através dessa técnica, a oportunidade de resolver suas diferenças, compondo interesses e promovendo a Justiça. A justiça social não é a que impõe o Estado, mas aquela que permite que as relações humanas se desenvolvam de maneira harmoniosa. É nesse sentido 
que o entrelaçamento desses ramos do conhecimento torna efetivo o comando constitucional de acesso à justiça.

Está posta a correlação entre os assuntos abordados. Ao perceber de forma estável a situação na qual está envolvida, o indivíduo tem habilidades para buscar no próprio sistema, em si mesmo e ao seu redor a "solução para o problema". Ou seja, propor nos moldes que a autocomposição sugere a solução mais eficiente para a situação conflituosa.

A solução do conflito levada à análise do Estado-Juiz muitas vezes não resolve a questão. Apenas posterga uma efetiva solução, pois as partes se sentem "incompreendidas e injustiçadas" e/ou vítimas da outra parte, do Juiz ou até mesmo da sociedade por não reconhecerem "o seu lugar" e por não perceberem suas responsabilidades por "ocuparem" tal posição sistêmica ou na rede de apoio. É como se fosse possível "olhar a questão de fora" e entender suas fragilidades e pontos fracos, bem como, perceber onde pode ceder para que o assunto seja, de fato, resolvido.

É esse o ponto de inserção vislumbrado: o reconhecimento e pertencimento gerado pela fortaleza psico-social-afetiva proporcionada por redes de apoio efetivas que são capazes de atuar positivamente quando da autocomposição de lides que batem à porta do Poder Judiciário. É o acesso à Justiça da forma mais genuína e próxima do conceito que se tem atingido nos últimos tempos.

\section{CONSIDERAÇÕES FINAIS}

Estudados os conceitos propostos do início deste trabalho, bem como, analisada a legalidade do Direito Sistêmico frente ao ordenamento jurídico brasileiro, percebemos sua inserção, bem como, sua relevância para a solução de conflitos judicializados na modalidade autocomposição - "método adequado de solução de conflito".

Discutida com atenção as redes de apoio, estas se mostram fundamentais para a compreensão do indivíduo no seu papel familiar, social, afetivo e como agente transformador de realidades, seja a própria ou a de terceiros. Essa consciência revela-se essencial quando se 
cogita uma solução oriunda das partes envolvidas para uma situação levada ao Poder Judiciário, conforme proposto inicialmente neste estudo.

Resta clara a complementariedade e a necessidade de se ter esse alicerce psicosocial-afetivo solidamente construído para o desenvolvimento das habilidades que o convívio social requer. Trata-se de conditio sine qua non para que a efetividade da solução encontrada pelas partes seja mais próxima da realidade fática, ou seja, de fato justa.

Percebe-se que os institutos se buscam e se complementam. Defendemos o papel prévio das redes de apoio para a formação de um indivíduo equilibrado; que apenas os inevitáveis conflitos sejam levados ao Poder Judiciário; mas que se permita a este, com o consentimento dos envolvidos, o emprego do Direito Sistêmico, como técnica de autocomposição. Compreendemos ainda, que os institutos em pauta devem interagir em um movimento de fluxo e de refluxo.

Tais ferramentas servem de suporte, inicial (para o caso das partes seguirem pelo caminho da heterocomposição) ou, quiçá, definitivo (para os casos que se findem na autocomposição) quando uma demanda - onde por trás existem pessoas com seus sentimentos expostos - não precisem esperar as burocracias (algumas necessárias outras nem tanto) para verem sua questão apreciada ainda que incialmente pelo Estado Juiz.

É nesse cenário que se vislumbra o acesso à Justiça. As ferramentas aqui expostas, se bem utilizadas, ajudam a alargar a visão da questão propondo uma perspectiva conciliadora. São aliadas importantes na promoção do autoconhecimento das partes envolvidas e aumentam o número de soluções consensuais de conflitos devido ao maior envolvimento/consciência das partes.

Pela perspectiva social, muitas vezes são pelas redes de apoio que novas práticas são conhecidas e incentivadas. E, ainda, pelo panorama jurídico configura-se, como já amplamente demonstrado, a sustentação pelo arcabouço jurídico aqui analisado o efetivo acesso a uma justiça justa, o que se anseia.

\section{REFERÊNCIAS}


ANTONUCCI, T.C., \& JACKSON, J.S. Social support, interpersonal efficacy and health: a life course perspective. In: CARSTENSEN, L \& EDELSTEIN, B.S. (orgs), Handbook of Clinical Gerontology. New York:Pergamin Press, 1987.

BRASIL. Constituição da República Federativa de Brasil de 1988. Disponível em http://www.planalto.gov.br/ccivil_03/Constituicao/Constituicao.htm. Acesso em: 27/02/2020

BRASIL. Código de Processo Civil brasileiro. Disponível em http://www.planalto.gov.br/ccivil_03/_ato2015-2018/2015/lei/113105.htm. Acesso em: $27 / 04 / 2020$.

BRITO, R.C.; KOLLER, S.H. Desenvolvimento humano e redes de apoio social e afetivo. In: CARVALHO, A. M. (Org.) O mundo social da criança: natureza e cultura em ação. São Paulo: Casa do Psicólogo, 1999.

CONSELHO NACIONAL DE JUSTIÇA. Resolução n. 125, 2010. Disponível em: https://atos.cnj.jus.br/atos/detalhar/atos-normativos?documento=156. Acesso em 22/08/2019.

CANOTILHO, J. J. G. Direito Constitucional e Teoria da Constituição. Coimbra: Almedina, 1998.

CARMO, M. S. do. Uma breve apresentação sobre a constelação sistêmico-fenomenológica. São Paulo, Atlas, 2015.

DIDIER JR. Fredie. Curso de Direito Processual Civil: introdução ao direito processual civil, parte geral e processo de conhecimento - 20ª ed.- Salvador: Ed.Jus Podivm, 2018.

FERRAZ JUNIOR, Tercio Sampaio. Estudos de Filosofia do Direito: Reflexões sobre o Poder, a Liberdade, a Justiça e o Direito - $3^{\text {a }}$ ed. São Paulo: Atlas, 2009

HELLINGER, B. Ordens do amor. São Paulo, Cultrix, 2001. A simetria oculta do amor: por que o amor faz os relacionamentos darem certo. São Paulo, Cultrix, 2006. . Amor à segunda vista: soluções para casais. Goiânia, Atman, 2011. 
MADALENO, A. C. C. A alienação parental, suas consequências e a busca de soluções à luz das constelações familiares e do direito sistêmico. Revista IBDFAM, n 12 - nov/dez 2015. Disponível em: http://www.rolfmadaleno.com.br/novosite/conteudo.php?id=1141\&gt; Acesso em 27/04/2020.

STORCH, Sami. Direito sistêmico é uma luz no campo dos meios adequados de solução de conflitos. Disponível em: https://www.conjur.com.br/2018-jun-20/sami-storch-direitosistemico-euma-luz-solucao-conflitos. Acesso em 22/03/2019.

ROSA, Amilton Plácido da. Direito Sistêmico e Constelação Familiar. Disponível em: http://www.cartaforense.com.br/conteudo/entrevistas/direito-sistemico-econstelacaofamiliar/16914. Acesso em 22/03/2019.

http://www.cnj.jus.br/noticias/cnj/86434-constelacao-familiar-no-firmamento-da-justica-em16-estados-e-no-df . Acesso em 22/08/2019.

https://tj-mt.jusbrasil.com.br/jurisprudencia/635750767/apelacao-apl16178420158110002273262018 -mt?ref=serp. Acesso em 26/04/2020. https://tj-rs.jusbrasil.com.br/jurisprudencia/625189971/apelacao-civel-ac-70076720119rs/inteiro-teor-625189977?ref=serp. Acesso em 26/04/2020. 